\title{
Care of hatching eggs before incubation
}

I*II

$e^{3}$

Library / Bibliothèque, Ottawa K1A 0C5

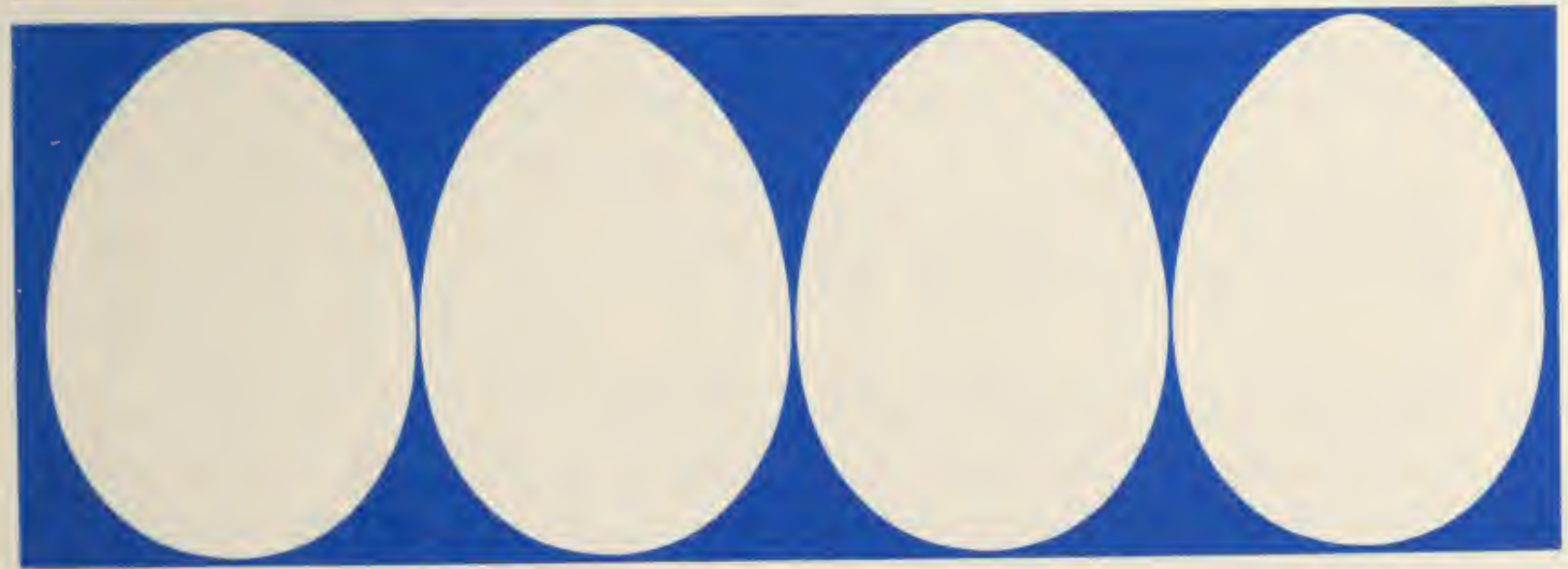

30.4

$2 \rho=2$

$0=0-13$

Canad'ä 
Agriculture Canada Publication 1573/E available from

Communications Branch, Agriculture Canada, Ottawa K1A 0C7

- Minister of Supply and Services Canada 1990 Cat. No. A63-1573/1990E ISBN: 0-662-17809-2

$\begin{array}{lll}\text { Printed } 1976 \text { Revised } 1983 & \text { Revised 1990 3M-06:90 }\end{array}$

Également disponible en français sous le titre Soin des oeufs avant l'incubation 


\section{Care of}

\section{hatching}

\section{eggs before \\ incubation}

F. G. Proudfoot and R. M. G. Hamilton

Research Station, Kentville, N.S.

\section{Introduction}

In Canada during 1988, about 570 million chicken eggs were placed in incubators. When such large numbers are involved, a small increase in percentage hatchability (the proportion of eggs that hatch) can produce impressive economic gains.

With improved techniques that successfully extend the storage time of hatching eggs, hatchery operators can handle their inventories with greater flexibility. Also, poultry breeders can increase the sample size of progenies and improve the efficiency of breeding operations.

It is well known that when hatching eggs are stored for long periods, hatchability is reduced. The reduction may occur rapidly or slowly, depending on environmental conditions, parental effects, genotypic differences, or a combination of these influences.

Hatchability is usually reported as either the percentage of fertile eggs hatched or the percentage of chicks hatched from all eggs placed in incubation. The percentage based on fertile eggs is more precise, provided that adequate techniques are used to distinguish between early mortality of the embryo and infertility of the egg. However, the percentage of saleable chicks hatched from all eggs set is often a useful measure, because it prevents the errors in estimates of hatchability that arise from inaccurate determinations of fertility.

\section{Storage temperature}

The importance of temperature for embryo survival was recognized before the turn of the century. The environmental temperature of viable eggs should be kept below "physiological zero" to maintain the dormancy of the embryos. Physiological zero is between 20 and $21^{\circ} \mathrm{C}$. A useful refrigeration unit for egg 
storage is shown in Fig. 1. It is important that eggs be collected and placed in an egg cooler frequently, particularly when environmental temperatures are extremely hot or cold.

Experiments have shown that there is a relationship between temperature and storage time. For short storage (up to 7 days), a storage temperature of 16 to $17^{\circ} \mathrm{C}$ is preferred, but for a longer storage period a temperature of 11 to $12^{\circ} \mathrm{C}$ should be used.

Recent evidence indicates that after eggs are collected and held overnight at 16 to $17^{\circ} \mathrm{C}$ hatchability will be enhanced by as much as $5 \%$, if they are warmed at $38^{\circ} \mathrm{C}$ for 5 hours the morning after the day of lay, followed by cooling at $12^{\circ} \mathrm{C}$ for 48 hours, then held up to 1 week at 16 to $17^{\circ} \mathrm{C}$ prior to setting. This may enable the embryo to develop to a stage at which it is most likely to survive while in the dormant stage during storage.

Some reports indicate that eggs should be warmed at a room temperature of $23^{\circ} \mathrm{C}$ for 18 hours before setting in an incubator.

When eggs are held at a low storage temperature of $11^{\circ} \mathrm{C}$, which is preferable for extended storage, prewarming at room temperature for 18 hours improves embryo viability and subsequent hatchability. However, at a high storage temperature of $16^{\circ} \mathrm{C}$, for short-term storage, prewarming just prior to setting may not be beneficial.

When eggs are moved from a storage temperature of $13^{\circ} \mathrm{C}, 15.5^{\circ} \mathrm{C}$, or $18.5^{\circ} \mathrm{C}$ to an environment at $23^{\circ} \mathrm{C}$, water condenses on the shell surface if

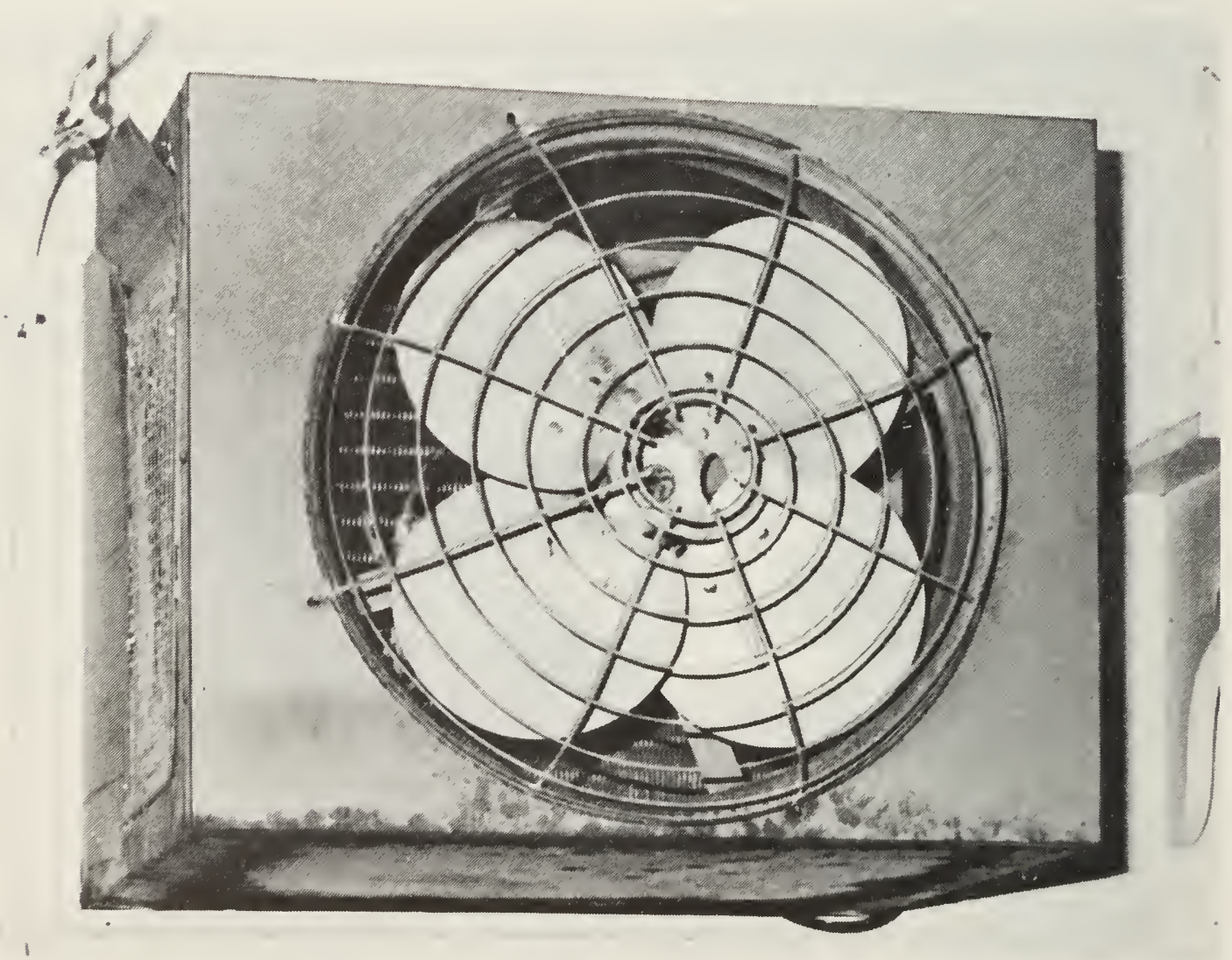

Fig. 1. A small refrigeration unit used to maintain temperatures in an egg storage room with a floor area of $15 \mathrm{~m}^{2}$. 
relative humidity exceeds 58,71 , or $83 \%$, respectively. Eggs do not sweat when they are prewarmed and kept enclosed until they have warmed up to environmental temperature.

\section{Relative humidity}

The rate of evaporation of water from eggs, and consequent weight loss, is greatly influenced by the relative humidity, temperature, and movement of the air or gas that surrounds them. Plastic enclosures probably prevent eggs from drying out too much because they limit the volume of air or gas around the eggs and eliminate air movement.

High relative humidity during preincubation storage is needed for optimum hatchability. Investigators found that high relative humidity, at $80-88 \%$, gave better hatchability than did relative humidities of $58-62 \%$ or $34-38 \%$. Another worker compared relative humidity levels of $75-82 \%$ and $80-90 \%$, but could not detect any significant differences in hatchability. A humidifier that can maintain such levels is illustrated in Fig. 2.

\section{Controlled atmosphere storage}

As early as 1738 , it was reported that dipping eggs in melted mutton fat prolonged the storage life of hatching eggs; the fat was removed with warm water

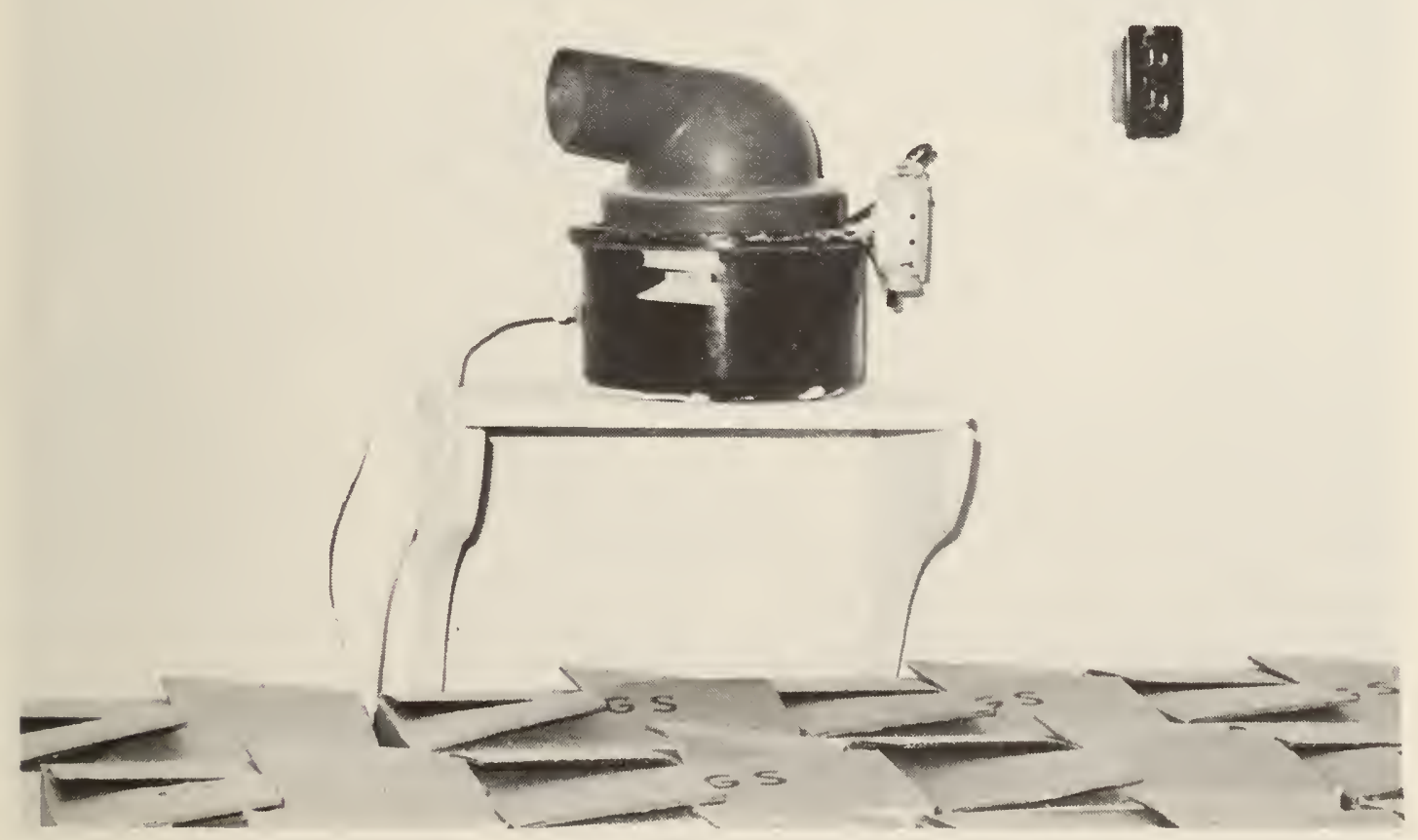

Fig. 2. An automatic humidifier used to maintain relative humidity at adequate levels in an egg storage room. 
before incubation. More recently, other methods such as treatment with oil have been devised for sealing the shells of table eggs to help preserve interior quality.

Studies have revealed that enclosing table eggs in plastic, as shown in Fig. 3, slows down the internal quality decline of table eggs during storage. The same practice has been applied to hatching eggs packed on fiber trays, and the advantages of enclosing them in plastic during storage, especially for long periods, are now well known.

Some investigators, however, have concluded that gains in hatchability for turkey and chicken eggs are not sufficient to warrant the use of plastic packaging if the storage period is only 1 week or less. One worker stored pedigreed eggs from 1 to 4 weeks enclosed in Cryovac, and concluded that the hatchability of fertile eggs of most hens could be improved by airtight packaging in Cryovac.

When eggs were stored for 6 days either in plastic bags or unpackaged, and at two temperatures, $11-13^{\circ} \mathrm{C}$ and $21^{\circ} \mathrm{C}$, the difference in hatchability between the packaging treatments was greater at the high storage temperature. Therefore, plastic packaging may be an advantage in higher-temperature environments, such as those met during transportation. When turkey eggs were closed in plastic during preincubation holding and shipping, they hatched better than similar eggs in standard packs.

A low-permeability film is effective for improved hatchability, but highpermeability films are of little or no benefit. Eggs should not be enclosed in plastic until they have cooled, and should be packed on clean fiber trays to reduce the

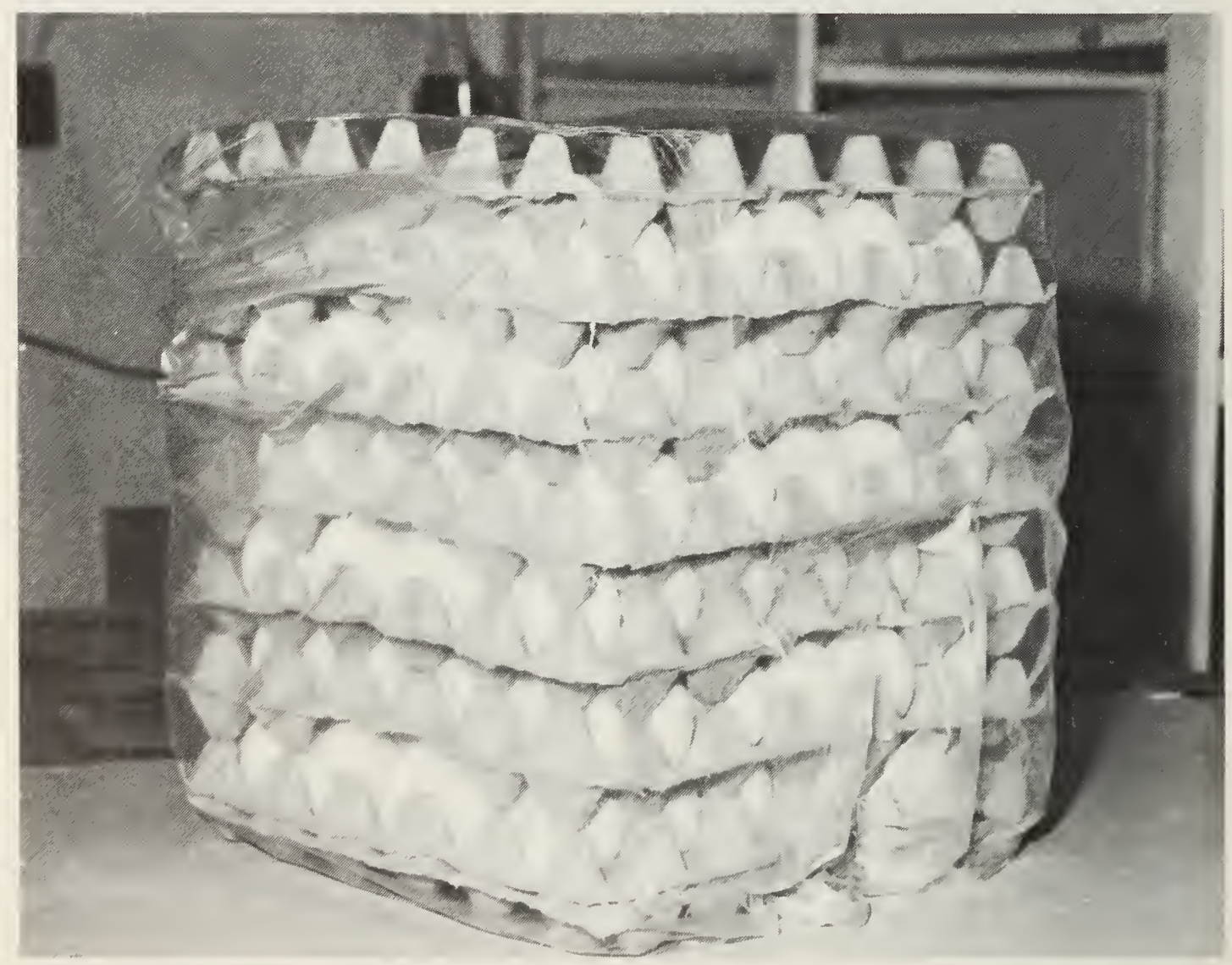

Fig. 3. Eggs enclosed in a plastic film for storage for 10 days or longer. 
chances of mold growth. A plastic shroud may be used to enclose eggs that are stacked on pallets.

The storage environment of chicken and turkey hatching eggs can be improved by the use of plastic enclosures, if preincubation holding temperatures are high, or if the storage period extends beyond 10 days for chicken eggs and a somewhat shorter period for turkey eggs.

The effect of a nitrogen storage atmosphere on hatching eggs has been reported. There is evidence that a Cryovac plastic enclosure with nitrogen improves hatchability when the storage time is long (more than 21 days). Fig. 4 illustrates the application of nitrogen gas to eggs enclosed in plastic.

When eggs are held for extended periods prior to incubation, it is important to extend the incubation period to 22 days before chicks are removed from the hatcher.

The best atmosphere for eggs in extended storage has probably not been established. High concentration of oxygen apparently has no harmful effect on eggs stored for 1 week or less, but severely affects the hatchability of eggs stored for longer periods. However, a. highly concentrated carbon dioxide atmosphere has been found harmful, particularly if storage extends beyond 1 week.

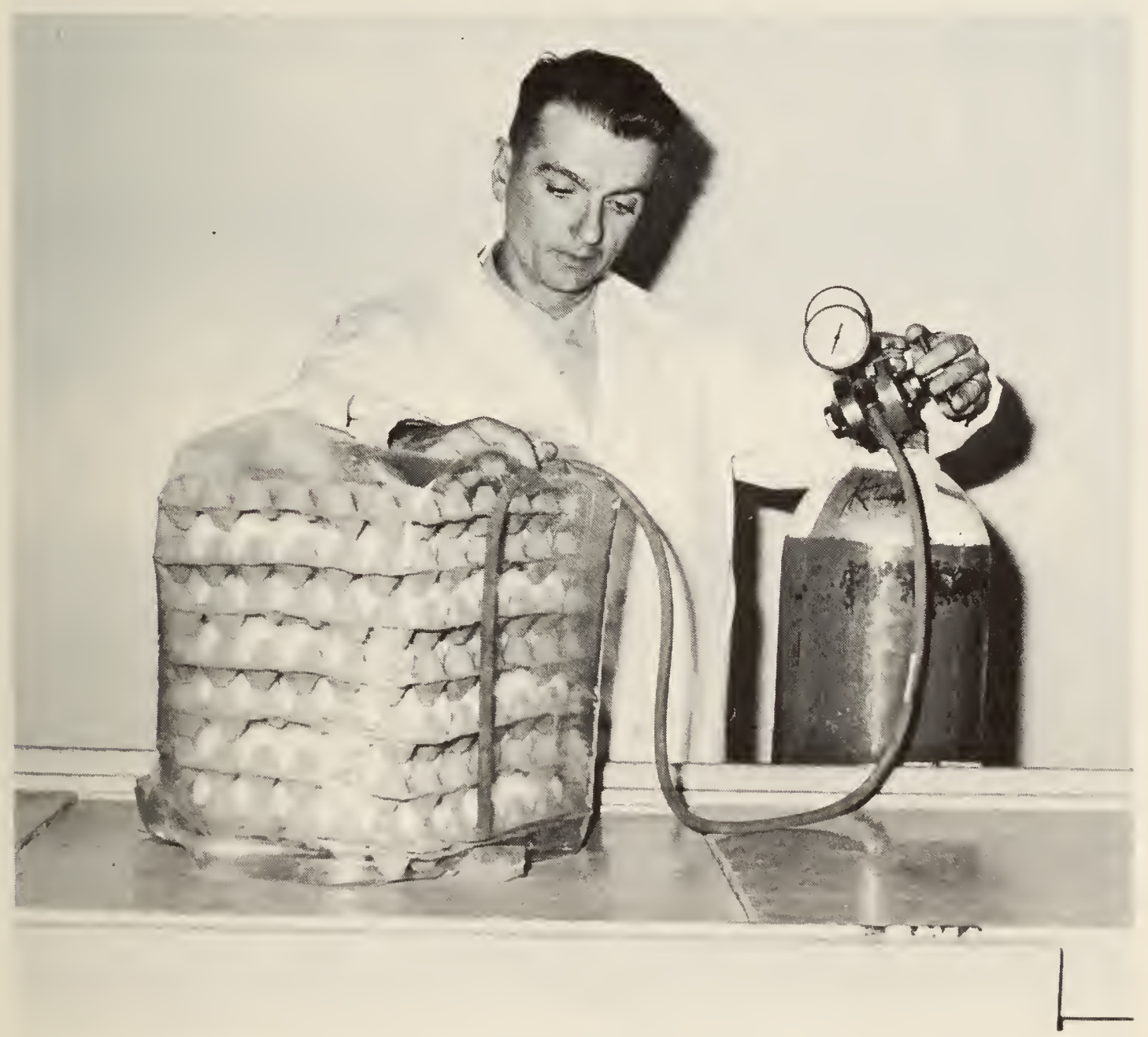

Fig. 4. Flushing an egg pack with nitrogen gas. 
Although some of the evidence is circumstantial, low levels of carbon dioxide and oxygen appear desirable for hatching eggs. Use of plastic enclosures flushed with nitrogen gas thus provides the best conditions for extended storage, such as is needed for primary breeders.

\section{Orientation and positional change}

Traditionally, hatching eggs have been packed and held before incubation in the small-end-down position. This packing orientation was thought to help maintain the air space in its original position and provide the highest rate of survival of embryos. However, it has been shown that chicken eggs packed with the small end up have better hatchability if they are held upright and not turned even for storage periods as long as 4 weeks.

Daily turning is beneficial when eggs are packed in the usual small-end-down position and stored for more than 2 weeks, but not when eggs are packed small end up and stored up to 4 weeks. Fig. 5 shows eggs held in each position, and Fig. 6 illustrates eggs stored in inverted cases so that they are held small end up.

According to the limited evidence available, when eggs are shipped the small-end-down orientation is preferable because of the chances of rough handling during transit.

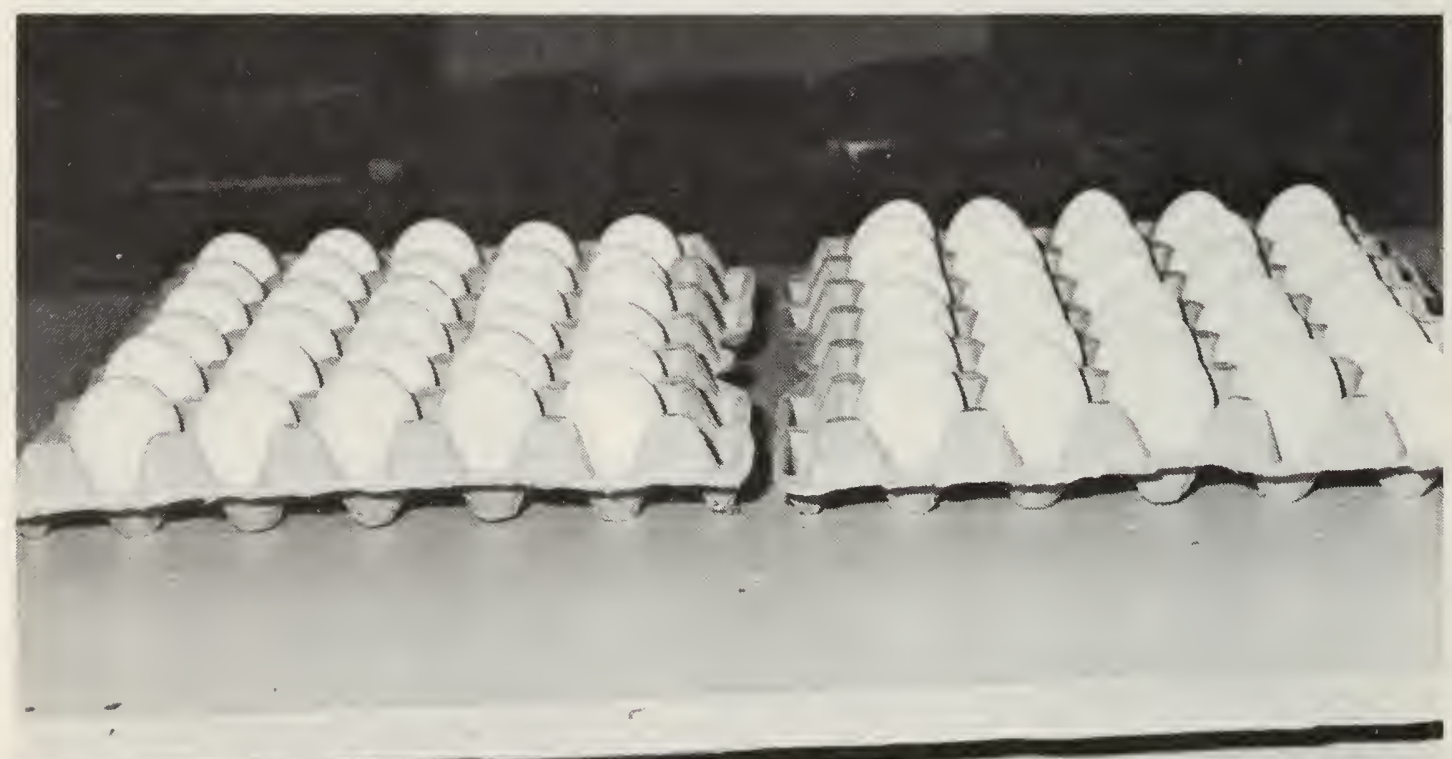

Fig. 5. On the left, eggs packed small end down; on the right, eggs oriented in the small-end-up position, which is preferred for eggs held for hatching. 


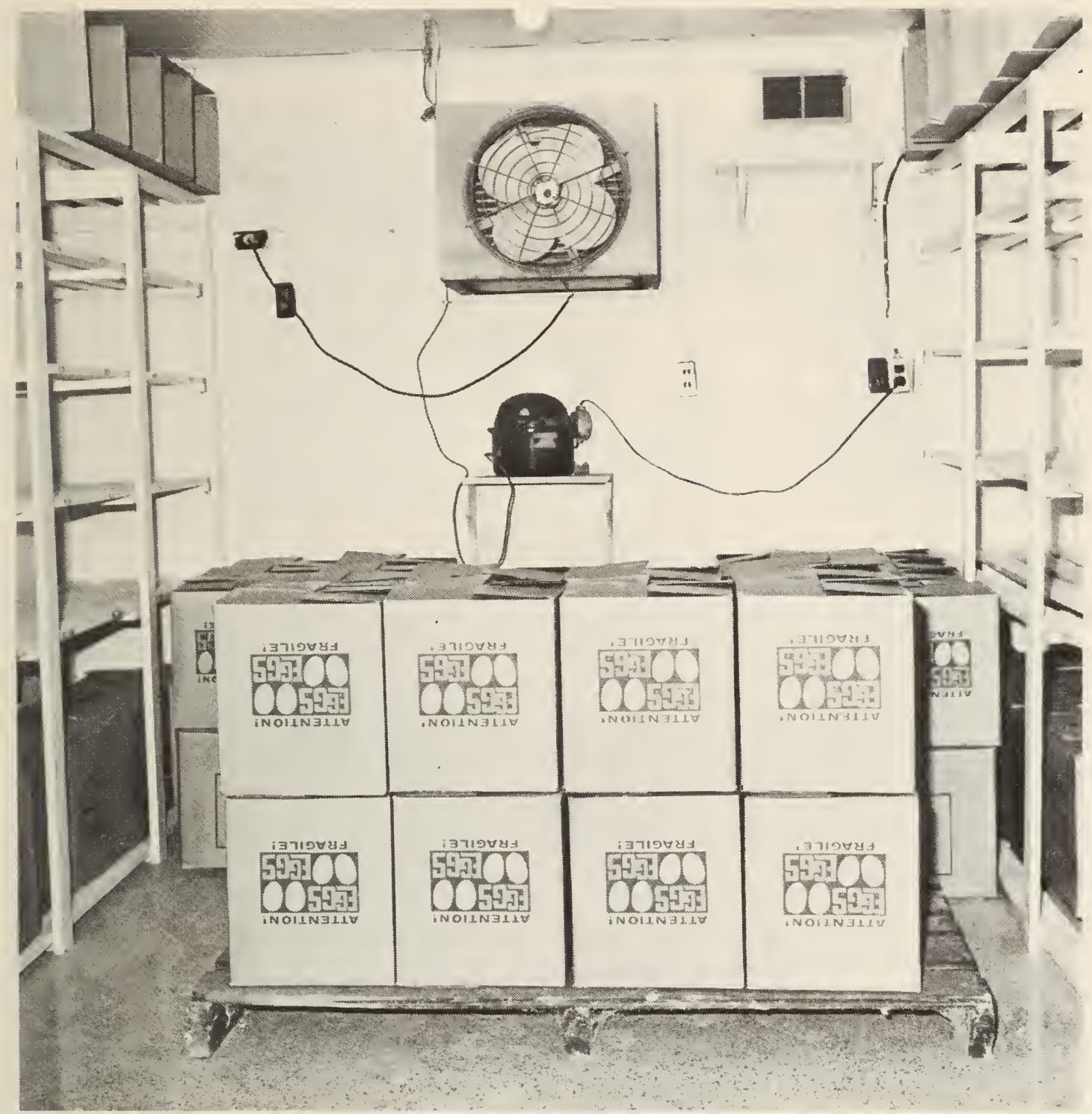

Fig. 6. Eggs packed in boxes or cases can be inverted and stored small end up on pallets without being turned every day.

Some work has been done on the general effect of egg orientation of the position of the yolk after storage up to 28 days. Eggs were cooked after storage in various positions. In eggs stored with the small end down, the yolks had gradually moved up toward the air space and after 28 days many were in contact with the shell membrane. Therefore, packing with the small end up may be beneficial, because it keeps the yolks near the center of the albumen and thus gives the dormant embryo greater protection from dehydration, temperature change, and adhesion to the inner shell membrane.

It is assumed that the orientation of the blastoderm and the central yolk position result in an improvement in hatchability when eggs are stored small end up. However, eggs should be placed in the incubator with the small end down. 


\section{Egg cleaning and fumigation}

It is best to use only clean eggs for hatching purposes. To be realistic, however, it is often necessary to clean eggs that have been soiled; if they were discarded from hatching the economic losses would be too great.

The harmful effects of cleaning eggs by washing can be kept to a minimum if they are washed properly. Washing should be done as soon as possible after the eggs have been collected. The washing water should contain a detergent and sanitizer and be kept at $38.0-40.5^{\circ} \mathrm{C}$. It is best to use a washer of the non-recycle type shown in Fig. 7

After washing, eggs should be sprayed with a fresh solution at a temperature of $40.5-43.5^{\circ} \mathrm{C}$, and containing $200 \mathrm{ppm}$ of free chlorine. Throughout washing the temperature of the eggs should be rising. This ensures that until the shell surface is

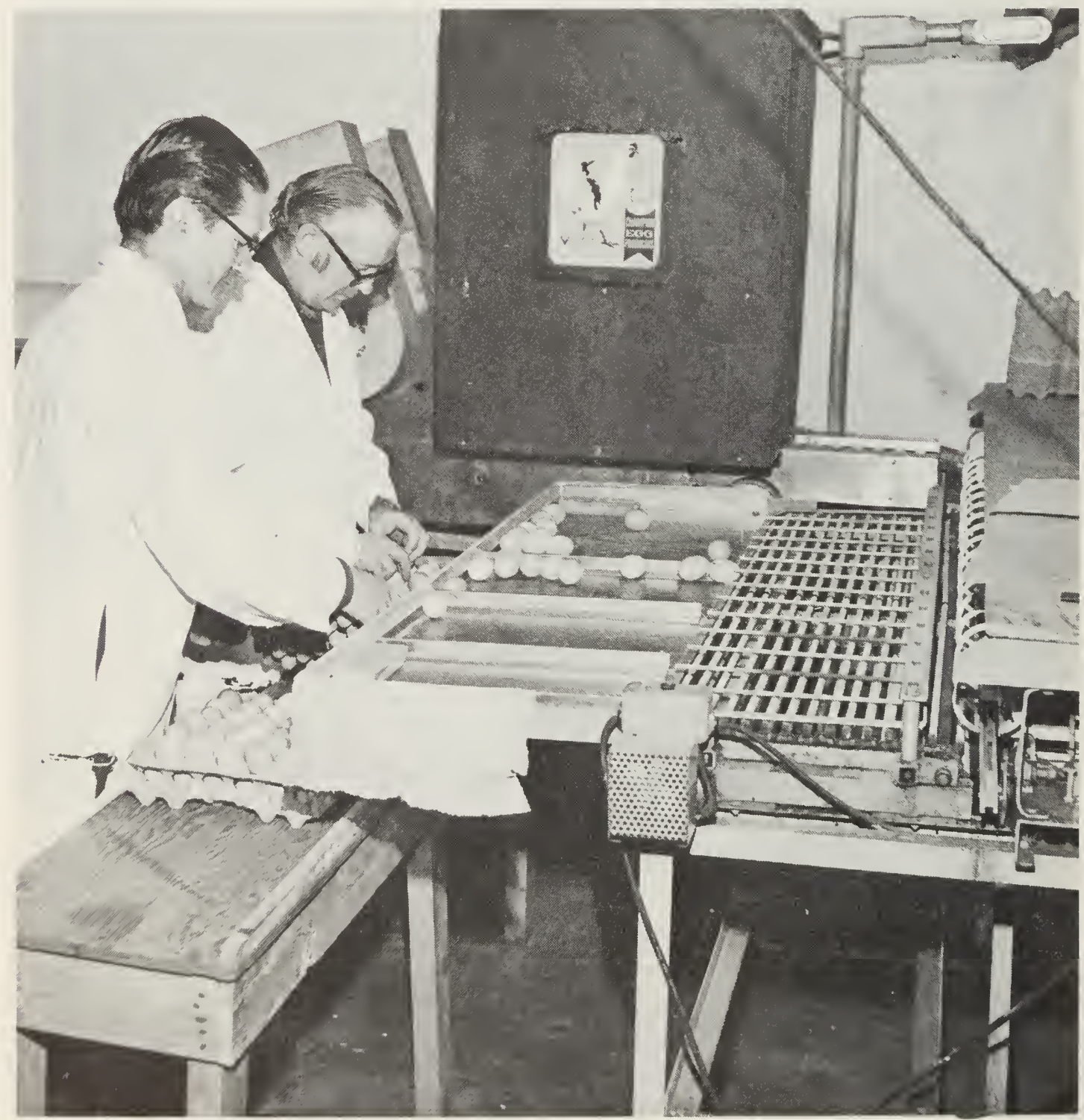

Fig. 7. Washing hatching eggs in a non-recycle washer. 
dry, the contents of the eggs tend to expand and exert an outward pressure, so that the washing solution cannot be drawn into the eggs through the shells.

Research has been carried out on the effects of preincubation fumigation on hatchability. Some of the important factors are the gas concentration, at $36 \mathrm{~g}$ potassium permanganate and $54 \mathrm{~mL}$ formaldehyde per cubic metre; the duration of fumigation, 20 minutes; the relative humidity, high; and subsequent ventilation for 24-72 hours before packaging, because otherwise adverse effects on hatchability can be expected. A respirator or gas mask should be used during fumigation, as shown in Fig 8.

This procedure does not appear to affect hatchability, even with a rising or falling temperature during fumigation. Although fumigation would usually be conducted within a few hours after lay, hatchability was not affected when eggs were fumigated after storage for as long as 3 weeks.

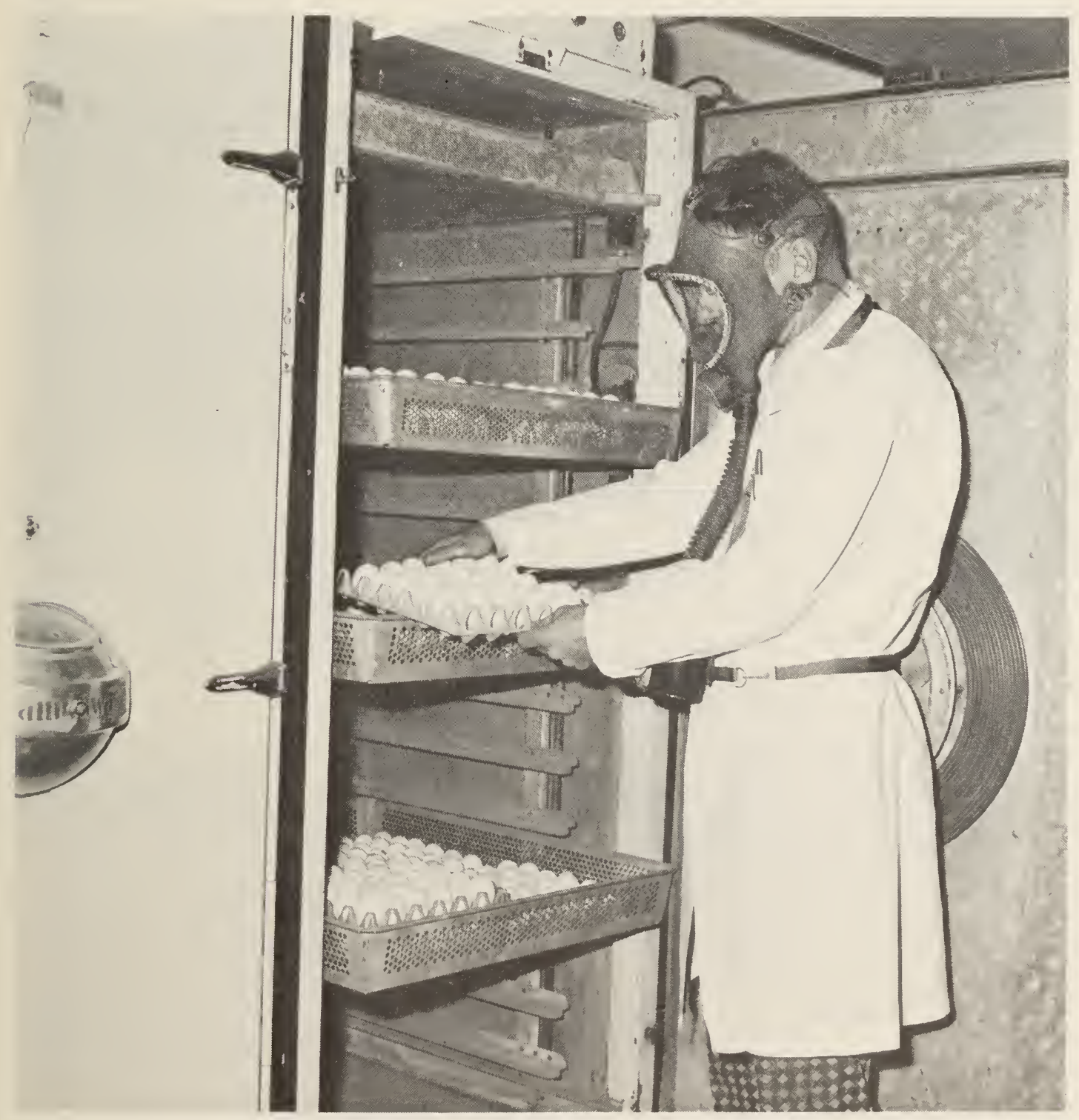

Fig. 8. Fumigation of hatching eggs in a modified incubation cabinet. A respirator or gas mask should be used during fumigation. The respirator must be equipped with the proper filter, which should be changed periodically. 


\section{Other factors affecting embryo survival}

Although it is usually preferable to set only eggs with sound shells, it is sometimes possible to use eggs with certain types of shell fractures. Although shell fracturing reduces hatchability, some eggs with basket-type cracks and hairline cracks may be salvaged by patching with plastic adhesive tape. Basket cracks in the equatorial area of the shell are more likely to destroy embryo viability than similar cracks on the large end of the egg. Hatchability has been better when hairline-cracked eggs were stored in nitrogen gas than when similar eggs were stored in a standard pack. Eggs should be handled carefully to minimize shell cracking, as seen in Figs. 9 and 10 where eggs are transferred to trays by hand and in a commercial operation.

The presence of blood and meat spots has no adverse effect on either the fertility or the hatchability of chicken eggs.

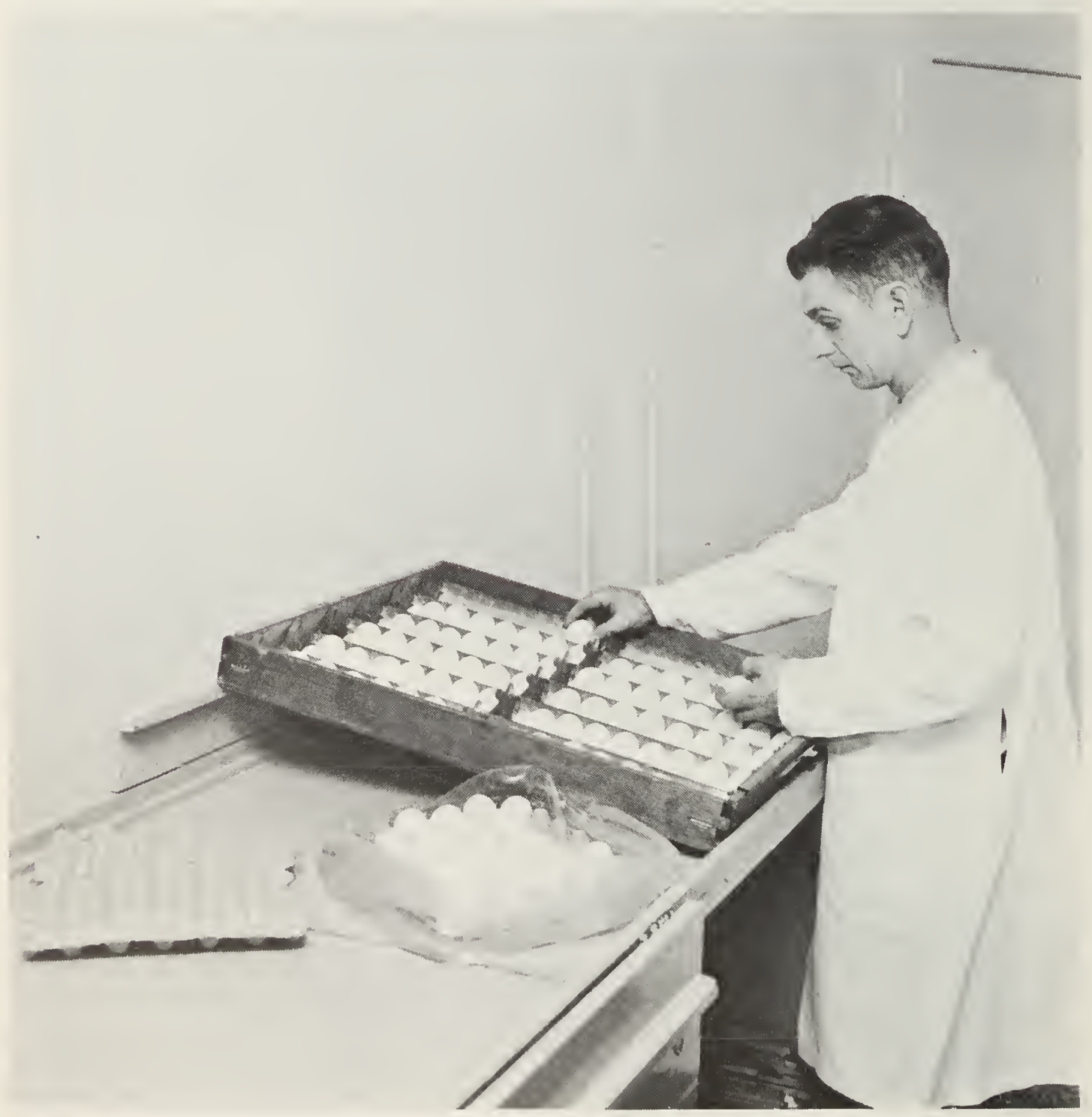

Fig. 9. Traying eggs for research purposes. 


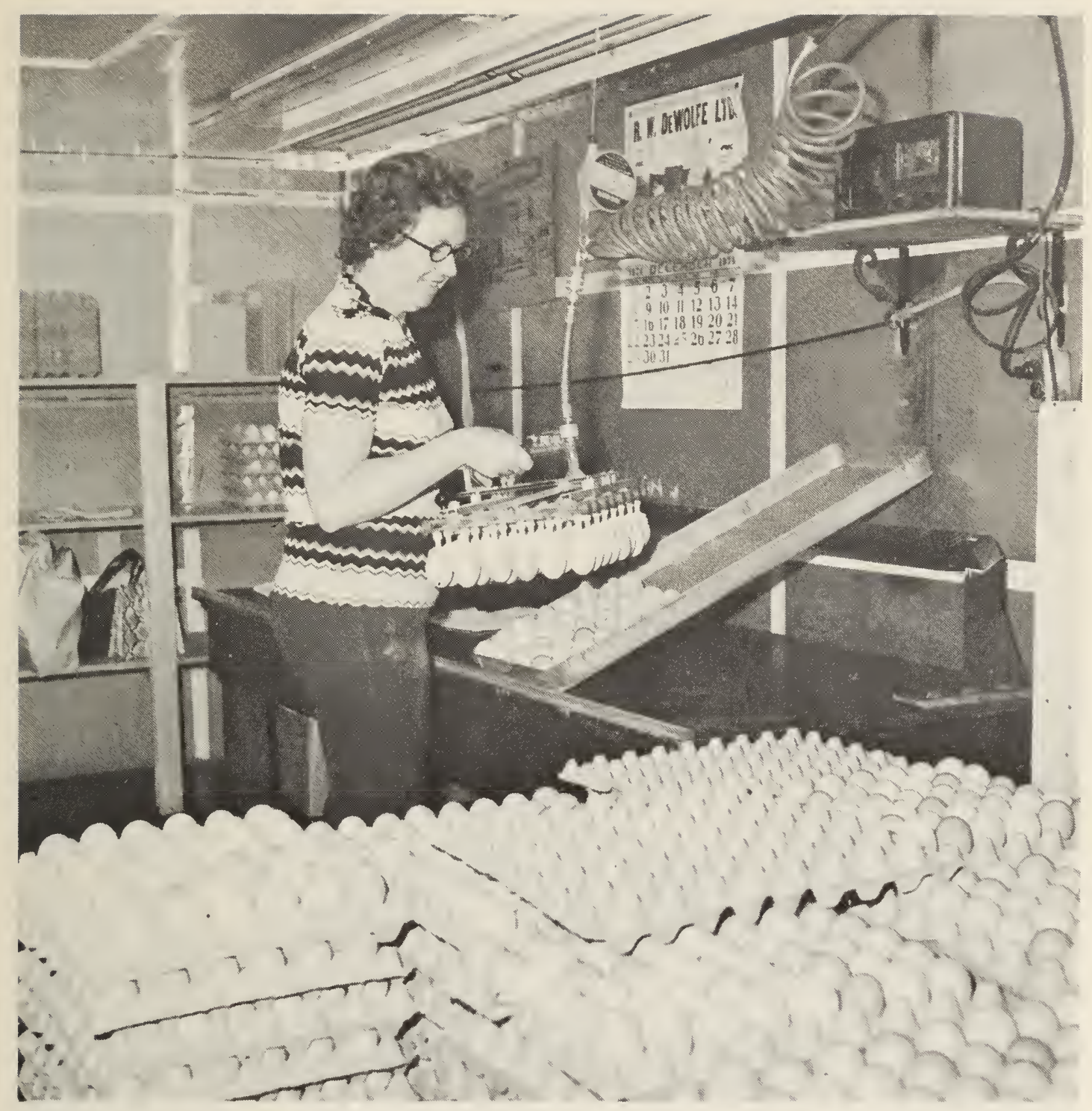

Fig. 10. Traying eggs in a commercial hatchery.

Double-yolked eggs and small eggs should not be kept for hatching. Multipleyolked eggs usually do not hatch, and small eggs produce small chickens, which is a disadvantage, particularly for broiler production. In Fig. 11, eggs are sorted according to size.

When eggs must be transported over long distances, they should be shipped and placed in incubation within 2 weeks after being laid.

\section{Egg storage effects on chick performance}

Several workers have reported that prolonged storage (up to 21 days) of eggs in standard packs at a controlled temperature and relative humidity had harmful effects on the performance of chicks hatched from them. The body weight of broilers at 8 and 9 weeks of age and viability of juvenile and adult birds were 


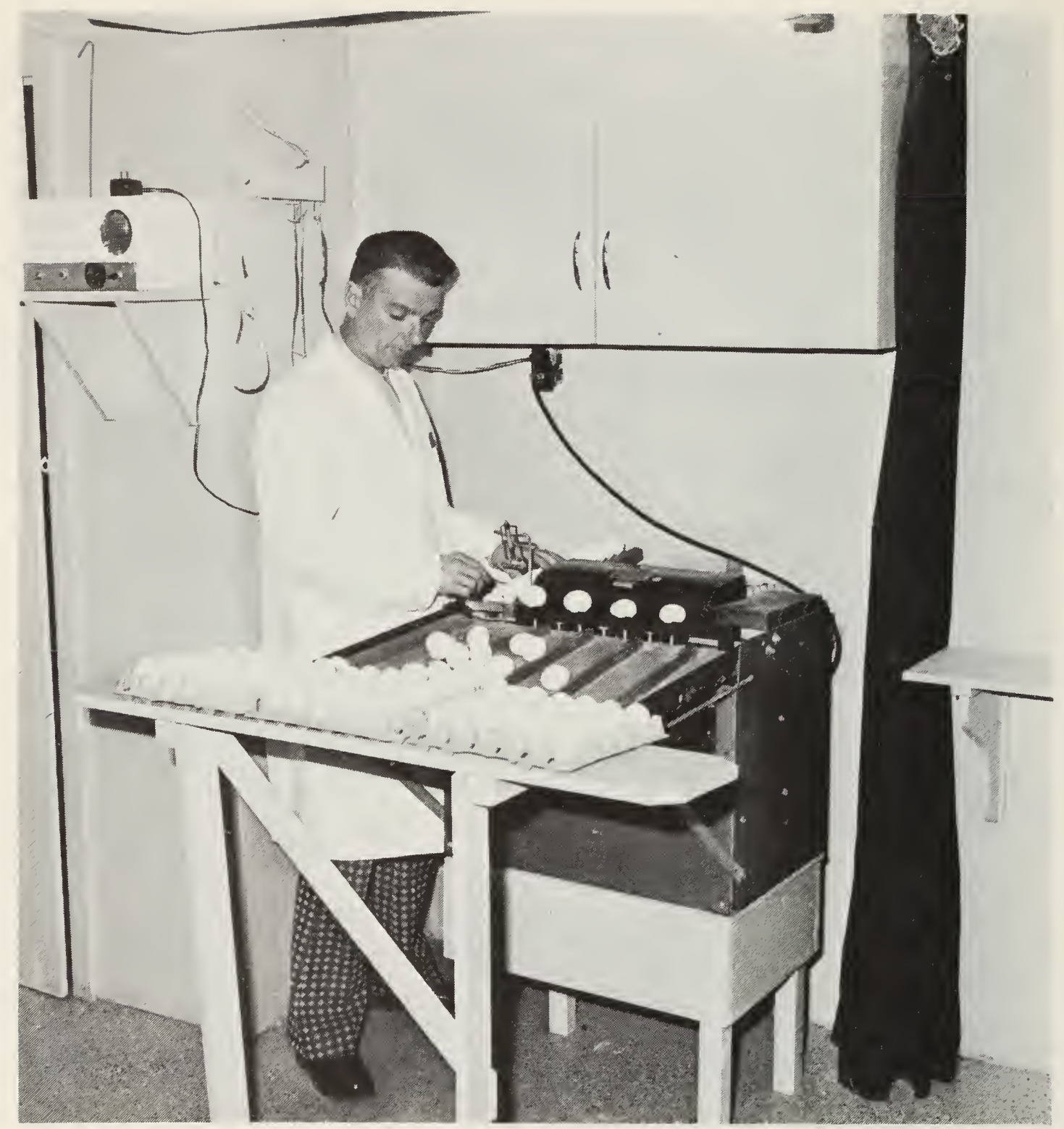

Fig. 11. Sizing to eliminate undersized and double-yolked eggs.

affected. In a study of this problem, both Leghorn and broiler-type hatching eggs were stored up to 28 days in plastic with nitrogen. The storage time did not affect the mortality of juvenile or adult birds, egg production, egg size, body weight, or shell strength. Thus, improved egg storage techniques not only increase hatchability, but also reduce or eliminate the adverse effects of less favorable storage conditions on the performance of birds hatched from stored eggs.

\section{Summary}

- A storage temperature of 16 to $17^{\circ} \mathrm{C}$ is recommended for eggs stored for 1 week, but a temperature of 11 to $12^{\circ} \mathrm{C}$ is better if the storage period extends beyond 1 week. 
- Prewarming is beneficial if eggs are stored at 11 to $12^{\circ} \mathrm{C}$. A prewarming temperature of $23^{\circ} \mathrm{C}$ for 18 hours before setting is recommended.

- Relative humidity of $80-88 \%$ during storage seems best.

- If eggs are stored for more than 7-10 days, or if preincubation temperatures are high, packing on fiber trays and enclosure in sealed plastic provide higher hatchability. A low-permeability film should be used.

- Hatchability can be improved further, for storage times of more than 2 to 3 weeks, if eggs are enclosed in a sealed, gas-impermeable film and the pack is flushed with nitrogen gas.

- Packing eggs with the small end up and storing in the upright position without turning results in better embryo survival at all stages of storage.

- Preincubation fumigation of hatching eggs should not adversely affect hatchability, if the proper gas concentration is used, if the fumigation time does not exceed 20 minutes, and if the eggs are properly ventilated before packaging.

- Eggs with limited shell fractures can be used for hatching if they are patched with plastic adhesive tape.

- Eggs with blood and meat spots hatch as well as normal eggs.

- Double-yolked eggs and small eggs should not be retained for hatching.

- There is now conclusive evidence that the harmful effects of prolonged egg storage on subsequent performance of birds are reduced or removed when eggs are stored according to the improved techniques described in this publication.

\section{Acknowledgments}

The authors wish to express appreciation for the photographic work done by A. T. Lightfoot, Research Station, Agriculture Canada, Kentville, N.S.

The authors also wish to acknowledge the helpful advice and assistance of members of the Poultry Sub-Committee of the Atlantic Provinces Agricultural Services Coordinating Committee, as follows:

L. W. Bradley, R. M. G. Hamilton, M. Proulx - Agriculture Canada

D. A. Ramey, J. Rutanga, M. C. Emond - New Brunswick Department of Agriculture and Rural Development

W. F. Dewitt, A. O. Oderkirk, H. N. Jansen, G. C. Smith - Nova Scotia Department of Agriculture and Marketing

D. C. Crober - Nova Scotia Agriculture College

L. R. Barnes - Newfoundland and Labrador Department of Rural and Northern Development Forestry.

G. D. Johnstone - Prince Edward Island Department of Agriculture and

\section{Bibliography}

Arora, K. L. 1965. Early embryogenesis of chickens and turkeys as related to the preincubation history of eggs and parental genotypes. Ph.D. Thesis, Washington State Univ., Pullman, WA. 142 pp.

Becker, W. A. 1960. The storage of hatching eggs and the post-hatching body weights of chickens. Poult. Sci. 39:588-590. 
Becker, W. A. 1964. The storage of White Leghorn hatching eggs in plastic bags. Poult. Sci. 43:1109-1112.

Becker, W. A.; Bearse, G. E. 1958. Preincubation warming and hatchability of chicken eggs. Poult. Sci. 37:944-948.

Becker, W. A.; Spencer, J. V.; Swartwood, J. L. 1964. The preincubation storage of turkey eggs in closed environments. Poult. Sci. 43:1526-1534.

Becker, W. A.; Spencer, J. V.; Swartwood, J. L. 1964. Hatchability of turkey eggs shipped in plastic eggs. Poult. Sci. 43:1539-1541.

Becker, W. A.; Spencer, J. V.; Swartwood, J. L. 1967. Hatchability of eggs held in plastic bags at two temperatures. Poult. Sci. 46:311-314.

Becker, W. A.; Spencer, J. V.; Swartwood, J. L. 1968. Carbon dioxide during storage of chicken and turkey hatching eggs. Poult. Sci. 47:251-258.

Bowman, J. C. 1966. Storage of hatching eggs: An experiment on alternative methods of storing chicken hatching eggs. Br. Poult. Sci. 7:219-225.

Cherms, F. L.. Jr.; McGibbon, W. H. 1961. Fertility and hatchability as affected by meat and blood spots. Poult. Sci. 40:808-809.

Cooney, W. T. 1943. Preincubation humidity variation effects on chicken egg hatchability. Tech. Bull. Ore. Agric. Exp. Stn. 2.

Davis, G. T.; Beeckler, A. F. 1962. Plastic packaging of eggs. I. Methods of packaging. Poult. Sci. 41:391-397.

Edwards, C. L. 1902. The physiological zero and the index of development for the egg of the domestic fowl, Gallus domesticus. Am. J. Physiol. 6:351-397.

Ernst, R. A.; Schroeder, J. P.; Pfost, R. E.; Holte, R. J. A. 1974. Field studies to evaluate commercial disinfectants for turkey hatching egg sanitation. Poult. Sci. 53:149-156.

Fairfull, R. W.; Gowe, R. S. 1981. Effect of age of egg on laying stock performance. Poult. Sci. 60:1655 (abstract).

Fletcher, D. A.; Orr, H. L.; Snyder, E. S.; Nicholson, A. O. 1959. Effect of oiling, packaging materials and addition of $\mathrm{CO}_{2}$ on quality of shell eggs held in storage. Poult. Sci. 38:106-111.

Friars, G. W.; Singh, J. 1967. An interaction effect of nitrogen storage with specific strains in the hatchability of turkey eggs. Can. J. Anim. Sci. 47:187191.

Funk, E. M.; Biellier, H. V. 1944. The minimum temperature for embryonic development in the domestic fowl (Gallus domesticus). Poult. Sci. 23:538540.

Funk, E. M.; Forward, J. 1951. Effect of humidity and turning of eggs before incubation on hatching results. Res. Bull. Mo. Agric. Exp. Stn. 554.

Funk, E. M.; Forward, J. 1960. Effect of holding temperature on hatchability of chicken eggs. Res. Bull. Mo. Agric. Exp. Stn. 732.

Gentry, R. F. 1974. Handle hatching eggs with care. Poult. Meat (May).

Gordon, C. D.; Siegel, H. S. 1966. Storage of pedigreed hatching eggs in Cryovac. Poult. Sci. 45:1369-1371.

Gowe, R. S. 1965. On the hatchability of chicken eggs stored in plastic bags flushed with nitrogen gas. Poult. Sci. 44:492-495.

Huston, T. M.; Palmer, J. R.; Carman, J. L. 1957. The effects of washing on the hatchability of the hen egg. Poult. Sci. 36:557-562.

Johndrew, O. F., Jr.; Baker, R. C. 1965. Producing high quality eggs. Cornell Ext. Bull. 1138. 
Kosin, I. L. 1956. Studies on preincubation warming of chicken and turkey eggs. Poult. Sci. 35:1384-1392.

Kosin, I. L. 1964. Recent research trends in hatchability related problems in the domestic fowl. World's Poult. Sci. J. 20:254-268.

Landauer, W. 1967. The hatchability of chicken eggs as influenced by environment and heredity. Conn. Agric. Exp. Stn. Monogr. 1 (revised).

Landauer, W. 1973. The hatchability of chicken eggs as influenced by environment and heredity. Conn. Agric. Exp. Stn. Suppl. to Monogr. 1 (revised).

McConachie, J. D.; Jerome, F. N.; Pepper, W. F. 1960. The effect of preincubation treatments on the hatchability of chicken eggs. Poult. Sci. 39:886-889.

Merritt, E. S. 1964. Preincubation storage effects on subsequent performance of chickens. Br. Poult. Sci. 5:67-73.

Olsen, M. W.; Haynes, S. K. 1948. The effect of different holding temperatures on the hatchability of hens' eggs. Poult. Sci. 27:420-426.

Proudfoot, F. G. 1964. The effects of plastic packaging and other treatments on hatching eggs. Can. J. Anim. Sci. 44:87-95.

Proudfoot, F. G. 1964. The effect of nitrogen and other gases on the hatchability of eggs stored in plastic bags. Can. J. Anim. Sci. 44:120-121.

Proudfoot, F. G. 1965. The effect of film permeability and concentration of nitrogen, oxygen and helium gases on hatching eggs stored in polyethylene and Cryovac bags. Poult. Sci. 44:636-644.

Proudfoot, F. G. 1966. Hatchability of stored chicken eggs as affected by daily turning during storage and prewarming and vacuuming eggs enclosed in plastic with nitrogen. Can. J. Anim. Sci. 46:47-50.

Proudfoot, F. G. 1966. The use of sealed Cryovac and polyethylene case liners with and without nitrogen gas for the preservation of hatching eggs. Poult. Sci. 45:105-108.

Proudfoot, F. G. 1967. The hatchability of chicken eggs with fractured shells after storage up to 42 days in nitrogen. Can. J. Anim. Sci. 47:115-122.

Proudfoot, F. G. 1967. The effect on hatchability of shipping eggs after storage for different periods of time in a nitrogen gaseous environment. Can. J. Anim. Sci. 47:137-138.

Proudfoot, F. G. 1967. Advance note on the hatchability of chicken eggs stored small end up. Can. J. Anim. Sci. 47:142-143.

Proudfoot, F. G. 1968. Hatching egg storage effects on hatchability and subsequent performance of the domestic fowl. Poult. Sci. 47:1497-1500.

Proudfoot, F. G. 1969. The effect of packing orientation, daily positional change and vibration on the hatchability of chicken eggs stored up to 4 weeks. Can. J. Anim. Sci. 49:29-35.

Proudfoot, F. G. 1969. The handling and storage of hatching eggs. Pages 127-141 in T. C. Carter and B. M. Freeman, eds. The fertility and hatchability of the hen's egg. Br. Egg Mark. Board Symp. No. 6, Edinburgh, Scotland.

Proudfoot, F. G. 1970. The influences of different preincubation holding temperatures on the hatchability of the chicken egg. Poult. Sci. 49:812-813.

Proudfoot, F. G.; Stewart, D. K. R. 1970. Effect of preincubation fumigation with formaldehyde on the hatchability of chicken eggs. Can. J. Anim. Sci. 50:453-465.

Proudfoot, F. G. 1972. Influence of an improved hatching egg storage method on the subsequent performance of broiler chickens. Can. J. Anim. Sci. 52:303308. 
Proudfoot, F. G.; Hulan, H. W. 1982. Effect of pre-incubation warming on the hatchability of hens eggs from normal and semi-dwarf parental genotypes. Can. J. Anim. Sci. 62:321-322.

de Reaumur. 1738. Sur la manière de conserver les œufs. Histoire de l'Académie Royale des Sciences. 1735:465-472.

Romanoff, A. L. 1960. The avian embryo. New York, NY: The MacMillan Company.

Romanoff, A. L.; Romanoff, A. J. 1949. The avian egg. New York, NY: John Wiley and Sons Inc.

Spratt, N. T., Jr. 1947. Development in vitro of the early chick blastoderm explanted on yolk and albumen extract saline-agar substrata. J. Exp. Zool. 106:345-365.

Steinke, L. 1967. The effect of vibration on the hatchability of chicken eggs. Arch. Gefluegelkd. 31:94-110.

Warren, D. C.; Roff, H. A.; Long, E. 1965. Hatchability of eggs stored in plastic lined egg cases. Poult. Sci. 44:1278-1280. 
Metric units

LINEAR

millimetre $(\mathrm{mm})$

centimetre $(\mathrm{cm})$

metre $(\mathrm{m})$

kilometre $(\mathrm{km})$

AREA

square centimetre $\left(\mathrm{cm}^{2}\right)$

square metre $\left(\mathrm{m}^{2}\right)$

square kilometre $\left(\mathrm{km}^{2}\right)$

hectare (ha)

\section{VOLUME}

cubic centimetre $\left(\mathrm{cm}^{3}\right)$

cubic metre $\left(\mathrm{m}^{3}\right)$

\section{CAPACITY}

litre (L)

hectolitre $(\mathrm{hL})$

WEIGHT

gram (g)

kilogram ( kg)

tonne $(\mathrm{t})$

\section{AGRICULTURAL}

litres per hectare (L/ha)

millilitres per hectare $(\mathrm{mL} / \mathrm{ha}) \times 0.014$ tonnes per hectare ( $\mathrm{t} / \mathrm{ha}$ ) kilograms per hectare $(\mathrm{kg} / \mathrm{ha})$ grams per hectare $(\mathrm{g} / \mathrm{ha})$

plants per hectare (plants/ha) $\times 0.357$

$\times 0.71$ $\times 0.45$

$\times 0.89$

$\times 0.014$

Approximate

conversion

Results in:

inch

inch

feet

mile

$\begin{array}{ll}\times 0.15 & \text { square inch } \\ \times 1.2 & \text { square yard } \\ \times 0.39 & \text { square mile } \\ \times 2.5 & \text { acres }\end{array}$

$\times 0.06 \quad$ cubic inch

$\times 35.31 \quad$ cubic feet

$\times 1.31 \quad$ cubic yard

$\times 0.035 \quad$ cubic feet

$\times 22$

gallons

bushels

oz avdp

Ib avdp

short ton

gallons per acre quarts per acre pints per acre fl. oz per acre tons per acre lb per acre oz avdp per acre plants per acre 
